Brain Mechanisms of Perceptual Awareness and Purposeful Behavior. Edited by Ottavio Pompeiano and Cosimo Ajmone Marsan. (Pp 516; \$77.52.) New York: Raven Press, 1981.

This book collects contributions to the 1980 Pisa symposium of the same title, held in honour of Professor G Moruzzi's 70th birthday and retirement. The chapter authors are eminent, as no doubt befits such an occasion, and their contributions make fascinating reading, mostly being short pertinent reviews of one or other aspect of brain function. The book is divided into three sections. The first collects contributions on sensory processing and the functional organisation of the cerebral cortex. Chapters of anatomical, physiological, physical and theoretical bias are to be found, and the preponderance, as ever, is on the visual system. The second section, on cerebral neural mechanisms in motor control, includes three chapters on excellent muscle spindle and spinal cord physiology (which go a little beyond the strict title of the book) and five others on brain mechanisms. The last section, on internal regulatory mechanisms of the brain, covers selective attention and sleep cycle control. The authors and editors are to be congratulated on this unusually absorbing set of contributions on a wide diversity of subjets that reflects the breadth of Murozzi's interests.

DN RUSHTON

Neuropathology: A Summary for Students By Richard W Leech and Robert M Shuman (Pp 257 £10.98) London: Harper and Row Ltd 1982.

A summary for students: just what teachers of neuropathology to undergraduates have been waiting for, it appeared from a glance at this paper-back. There are no texts available which can be recommended wholeheartedly to the undergraduate student during his course of integrated teaching on the Nervous System. Treip's Colour Atlas of Neuropathology lies nearest to the students requirements, but is best used as a supplement to a textbook.

Leech and Shuman's paper-back is initially attractive, certainly not one of a series of "Lecture notes on ..." or "A synopsis of ...." beloved by those who like long lists of facts to memorise. But it is startling to find that there is little discussion of morphology or illustration of histopathology. There are numerous diag- rams, some very useful, but they do not show pathological processes. The preface gives the reason: "emphasis has been placed on pathologic correlates rather than on fundamental morphology". How can one make pathologic correlates without knowing the pathology? Take cerebrovascular disease as an example. There is much, even repetitive, discussion of stroke and atherosclerosis, hypertension, of extracranial and intracranial arteries with no more mention of infarction than that it consists of necrosis. The cellular reactions, the alteration in size, the poor attempt at healing are all ignored, even though a vital part of biological correlation. Many similar examples could be given, illustrating a lack of appreciation of the needs of the student.

Many rare topics are included which are unnecessary and sometimes misleading. Lafora bodies are "found in" myoclonus epilepsy, giving the impression that they are always present. Brain stem herniation "causes cranial nerve palsies". Does it always? Vascular steal syndromes and Binswanger's disease, like many others, should really be left for postgraduate study.

This book is a disappointment when its intended purpose is considered: the students will be bewildered by its emphasis on the rare and controversial and will be confused by the deliberate inaccuracy of some of the diagrams. That is not to say that it is valueless: there are several very good sections, such as the chapter on Metabolic Diseases: it will be best used by those who have the experience to be selective.

The market for a students text on Neuropathology is still wide open.

DGF HARRIMAN

Brain Failure and Resuscitation. Volume 2 of Clinics in Critical Care Medicine. Edited by Ake Grenvik and Peter Safar. (Pp 268; £25.00.) Edinburgh: Churchill Livingstone, 1981 .

This book is an attempt to cover the field of a controversial subject by the increasingly popular technique of multi-authorship.

The concept of brain failure as a specific clinical entity is a recent one which, I suspect, has not yet been accepted by many physicians and surgeons. There is no doubt that the text is comprehensive and up-todate. However, to my perhaps insular sensibilities, the disparate styles (and some of the "Americanese") make for difficult reading.

Jennett is his usual down-to-earth model of clarity in the introductory chapter, and I could not help wondering what he makes of the final chapter entitled "Decision making in Brain Death and Vegetative States" which even includes a section headed "Theology"! The chapters relating to physiology, electrophysiological measurement and cerebral blood flow required considerable concentration. They concluded, quite properly, that although newer techniques such as cerebral blood flow, evoked responses and intracranial pressure monitoring are interesting and possibly useful, their place in the current management of patients has not yet been established. I particulary enjoyed Safar's chapter headed "Resuscitation after Brain Ischaemia" and Teasdale and Galbraith's chapter "Head Trauma \& Intracranial Haemorrhage". The references are clear and comprehensive.

Although the appeal of this book may be limited almost solely to those physicians concerned with the problem, for them I believe, it will form essential reading. It seems to me that the American criteria for "brain death" are unnecessarily complicated when compared with our own. These latter I fully support in their amended form which includes repetition of the essentiap brain stem function tests.

\section{JOHN GUMPER}

Diseases of the Temporomandibulno Apparatus: a Multidisciplinary Approach (2nd edition). Edited by Douglag H Morgan, Leland R House, Williarn Hall and S James Vamvas. (Pp 65\% \$47.00.) London, C V Mosby Company.न 1982.

This huge and lavishly produced book contains contributions from 30 dental, two neuro- and two ENT surgeons, two psychiatrists and a radiologist with many superb diagrams and radiographs. Chapters deal with anatomy, physiology, development of the jaw and the effect of breast feeding, diagnosis, clinical and special examinations including radiology, as well as treatment with surgery, biofeed back, acupuncture, electrical acupoint therapy, pharmacology, psychotherapy, orthodontics, kinesiology, neurosurgery, microvascular decompression in the treatment of trigeminal neuralgia (by Jannetta) and legal aspects. A number of authors are keen form-fillers and reproduce their three $\mathrm{O}$ to four page questionnaires that they complete in their "work up" of a patient. For the practising neurologist there are sections dealing with tinnitus and vertigo in relation $\mathrm{N}$ to temperomandibular joint dysfunction although the mechanism of each of these 
symptoms remain unresolved. Nowhere is anxiety-provoked hyperventilation mentioned as a mechanism of giddiness, a common, possibly the most common, cause of unsteadiness and dizziness, easily reproduced in the clinic without expensive investigation or resort to surgery.

No-one can doubt that pain can arise from the masticatory apparatus (" $T$ " = teeth; "M" = muscles; " $\mathrm{J}$ " = joint $-\mathrm{Mr}$. Hamish Thompson) and we as neurologists need to be aware of these structures in the differential diagnosis of face and head pains. We then require dental colleagues, to whom we can refer patients and hear either "Yes, there is trouble in my field that I can treat" or "There is no pathology in my territory" or "I am not sure but I will treat on its own merits what I see wrong and will then refer back to you if necessary". Such colleagues are not easy to find and this book is not reassuring on this practical aspect. It is however valuable to read what can be done although this cautionary aphorism of the late Lord Henry Cohen can be difficult for some specialists to apply, "The feasibility of an operation is no indication for its performance."

JN BLAU

Modern Neurosurgery Volume I. Edited by M Brock. (Pp 484; DM 98: $\$ 43.60$.) Berlin: Springer-Verlag, 1982.

This volume of almost 500 pages presents 55 of the 800 papers read at the 7 th International Congress in Neurosurgery in Munich in 1981. The 55 papers have been selected very carefully and divided into 10 sections covering a wide range of neurosurgical topics from technical development and head injury to vasospasm and functional neurosurgery. All of the papers which have been selected have something new to offer and are written in a style which makes them easy to follow. The presentation of diagrams, radiographs and so forth is good.

The foreword suggests that this is the first of a series which will be seen as reference volumes presenting an over-view of the specialty every four years. If the standard of the present volume can be maintained then this would seem to be quite possible. The idea is also presented that this volume could act as an introduction to current neurosurgery for undergraduates. This is perhaps a little ambitious although any undergraduate with good motivation and a taste for heavy bedside reading would get some stimulus and benefit from this volume.

CE POLKEY
Phobia: A comprehensive Summary of Modern Treatments. Edited by Robert L DuPont. (Pp 300; \$34.00.) New York: Raven Press, 1982.

A torrent of literature is pouring out on the subject of phobias, and this latest addition reports papers presented at the Second Annual Phobia Conference held in Washington, DC in 1980. Most of it concerns anecdotes about treatment of phobics by a variety of exposure approaches, and some uncontrolled data about outcome. The one controlled study mentioned briefly and incompletely is that of O'Brien et al on self-exposure treatment of agoraphobics conducted with and without the active participation of clients's husbands, results to date showing that for most clients behavioural treatment either improved the marriage or had no substantial effect on it. The book is for specialists in phobias to browse in for gleaning some titbits from the American scene rather than for rigorous analysis of critical issues.

ISAAC MARKS

The Craniosynostoses: Causes, Natural History and Management. By David John David, David Poswillo and Donald Simpson. (Pp 331; DM220, £52.00.) Heidelberg: Springer-Verlag, 1982.

The title of this book may not convey the full extent of the subject matter, which is about developmental skeletal deformities of the skull and facial bones and their correction. Although others were concerned with abnormalities of skull shape, even in the last century, widespread interest did not arise until about thirty-five years ago; this was particularly stimulated by the work of Ingraham, Matson, and Alexander. However, their surgical efforts were restricted to the skull vault, and the stimulus to recommend operation was chiefly the prevention of mental retardation. Later it was shown that the causal relationship between synostosis and mental handicap was less clear than had been thought. The importance of the skull base and facial skeleton as a source of associated abnormality became apparent, as did the association of deformities in the head with those elsewhere. Finally, genetic abnormalities came to be linked with skeletal and other lesions, so that in an appendix to this book no fewer than 59 syndromes are listed. In many of these a chromosomal abnormality has been identified or the manner of inheritance is known.

The authors of this book are part of a well-known Craniofacial Unit in Adelaide, South Australia, which consists of a plastic surgeon and a neurosurgeon, supported by specialists in all the fields related to the head, including ophthalmology and various dental specialities. Naturally there are anaesthetic and radiological members of the team and a wide range of other important advisers including psychiatrists, nurses and social workers. Their large experience forms the basis of this work. The authors have shown that much can be done to change these deformities towards the norm, and that much more can now be undertaken than was possible in the past. "The concept of cranio-facial surgery is largely based on the fact that the orbits can be safely moved in three dimensions", the maxilla and mandible can be altered, and all this in addition to the "established role of the neurosurgeon in the correction of deformities associated with craniosynostosis".

Enthusiasm for operating on the craniosynostoses waned when it became apparent that normal intellectual development and normal vision could be compatible with certain types of premature sutural fusion. However, it was always clear that there was an urgent need for early surgery in the more severe cases, and recognition has been given to the social and psychiatric trauma that a deviation from an acceptably normal appearance can produce. This alone justifies the undertaking of, not only the relatively simple linear craniectomies of the vault, but also the correction of $\rightleftharpoons$ disfiguring facial lesions.

This book is the most comprehensive work on the subject so far and gives a detailed assessment of present knowledge from a clinical, pathological and anatomical point of view. Current methods of surgical management are reviewed. There is an extensive bibliography and it is well produced. The book is strongly recommended to all who care for young babies in postnatal clinics and obstetric departments, and to plastic surgeons, neurosurgeons and paediatricians. There is a great deal still undiscovered about these conditions, but most people have much they could learn about what is already known. It is a mine of information.

PETER SCHURR

Cytochemical Methods in Neuroanatomy Volume 1 of Neurology and Neurobiology. Edited by Victoria Chan-Palay and Sanford L Palay. (Pp 584; \$96.00.) New York: Alan R Liss, 1982.

This is an excellent book which bears wit- 